\title{
An investigation of the immune response of patients suffering from anorexia nervosa
}

\author{
C. A. Armstrong-Esther $\dagger$ \\ Ph.D., B.Sc., S.R.N., R.N.T., \\ Dip.Ed., M.I. Biol.
}

A. H. CRISP $\ddagger$

M.D., F.R.C.P.(E), F.R.C.Psych.

\author{
J. H. LACEY** \\ M.B., M.Phil, M.R.C.Psych.
}

\author{
T. N. BRYANT** \\ Ph.D., B.Sc.
}

\section{Departments of $†$ Human Biology and Health, and **Microbiology, University of Surrey, Guildford $\ddagger$ Academic Department of Psychiatry, St George’s Hospital Medical School, London, SW17}

\begin{abstract}
Summary
Patients suffering from anorexia nervosa rarely appear to develop the common cold or influenza. This study examines the immunological response of fifteen female anorexia nervosa patients of both the vomiting and carbohydrate-abstaining type and compares them with a control population matched for age and occupation. Both anorectics and control populations received the admune influenza vaccine. Initially both groups had similar haemagglutination inhibition titres against the three different viral antigens: A/HK; A/PC; A/Eng. However, the anorectics showed over a 2-month period a higher titre of antibody especially to the Hong Kong virus: this was significant. Cellular immune responses were measured using a tuberculin and a macrophage inhibition test, no significant difference between the two groups was observed. These results which support the clinical findings are discussed.
\end{abstract}

\section{Introduction}

Patients suffering with anorexia nervosa rarely appear to develop the common cold or influenza. Furthermore, contrary to previously held opinion, they seldom die from infective illness (Crisp, 1967, 1970; Dally, 1969). According to Dally (1969) some patients complain that after regaining weight they lose this immunity and become more susceptible to infection. In contrast to the supposed resistance to, or avoidance of viral infections, for these patients are often special isolates, Dally reported that five patients out of a population of 140 developed tuberculosis during starvation or shortly after regaining their target weight. More recently, Crisp, Palmer and Kalucy (1976) have reported that two

* Requests for reprints to Dr J. H. Lacey, Department of Psychiatry, Middlesex Hospital, W1. out of twenty-eight male cases had active pulmonary tuberculosis in contrast to there being no such illness amongst 300 female patients. The two males were characterized by regular vomiting and purging and displayed the profound metabolic disturbance associated with this particular pathological form of anorexia nervosa (Crisp, 1970). To examine these clinical findings, humoral antibody response to influenza, haemagglutination inhibition (HAI) and cell-mediated immunity (CMI) against tuberculin were measured in a group of patients suffering from anorexia nervosa and a control group of healthy subjects.

\section{Materials and methods \\ Study population}

The test group consisted of 15 female anorectics receiving either in- or out-patient treatment. Their age range was from 16 to 36 years (mean $21 \cdot 7$ years). The control population comprised school children, undergraduates and technical staff and were age (mean 20.6 years) and sex matched. All participants were normal with respect to respiratory function as demonstrated by medical history, physical examination, chest X-ray and vital capacity. None of the subjects had a history of influenza in the preceding 12 months. Subjects with a history of allergy were excluded. During the course of the study, records of infection were kept; none of the subjects developed influenza.

Vaccines. Each 0.5-ml dose of Admune influenza vaccine contained: A/England/42/72, 400 i.u., A/Port Chalmers/1/73, 400 i.u., and A/Hong Kong/ $1 / 68,360$ i.u. In addition, each subject received intradermally $0 \cdot 1 \mathrm{ml}$ tuberculin purified derivative (PPD) of Mycobacterium tuberculosis. 
Extraction of sera and treatment to remove nonspecific inhibitor. Blood was collected into sterile universal bottles and after clot retraction serum was pipetted off and centrifuged at 1500 r.p.m. for 10 min, transferred to a sterile bijou and stored at $-20^{\circ} \mathrm{C}$. To remove non-specific inhibitors, serum was diluted 1 in 4 with receptor destroying enzyme (RDE) Wellcome Reagents, and incubated for $18 \mathrm{hr}$ at $37^{\circ} \mathrm{C}$, the enzyme was inactivated by incubating the serum at $56^{\circ} \mathrm{C}$ for $1 \mathrm{hr}$.

Red blood cell. Human type ' $\mathrm{O}$ ' $\mathrm{Rh}+\mathrm{ve} \mathrm{RBc}$ were used and on each test occasion taken from the same subject. The cells were washed three times using veronal buffer and $0.1 \%$ bovine plasma albumin (BPA) then counted using a Celloscope 401 to give a dilution of $60 \times 10^{9}$ cells $/ 1$ ( $0.5 \%$ suspension).

Virus culture. Fertile, specific pathogen-free (SPF) hen eggs were incubated at $38^{\circ} \mathrm{C}$ for 9 days in $55-60 \%$ humidity. Viruses were inoculated allantoically and harvested 3 days later.

Antibody assay. Haemagglutination and haemagglutination inhibition tests were carried out using microtitre plates (Flow Laboratories Ltd). The method used was that of Heirholzer, Suggs and Hall (1969).

Macrophage inhibition. The test for inhibition of macrophages was carried out with peritoneal macrophages obtained from unimmunized guineapigs using the method of Rocklin, Meyer and David (1970).

Protocol. Initially, $10 \mathrm{ml}$ of blood were taken by venepuncture and HAI estimation carried out, thereafter each subject was given, by intramuscular injection, $0.5 \mathrm{ml}$ commercial inactivated influenza vaccine. A further $10 \mathrm{ml}$ venous blood were collected on the 10th and 28 th day after vaccination. On day
48, a tuberculin test was carried out and $48 \mathrm{hr} z$ later the site of injection was examined and the re- $\stackrel{\mathbb{Q}}{\complement}$ active zone measured and recorded. On day $50,$. $20 \mathrm{ml}$ venous blood were taken to determine final $\overrightarrow{\vec{F}}$ haemagglutinating antibody titre and cellular im- $\stackrel{?}{+}$ mune response (CIR) to tuberculin.

\section{Results}

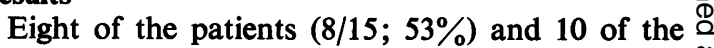
controls $(10 / 15 ; 67 \%)$ were positive to the tuber- $\%$ culin test. No significant difference was observed in $\overrightarrow{0}$ the macrophage inhibition test of the two groups. The results for haemagglutination titres showed con- $\vec{\omega}$ siderable individual variation, therefore the results $\frac{O}{0}$ have been pooled and the means for each group (patients and controls) calculated.

The amount of carbohydrate ingested was variable within the anorectic population. There were three $\mathrm{E}_{\mathrm{W}}$ main groups: in-patients on a high carbohydrate $N$ diet, out-patients before treatment on a low carbo- of hydrate diet and out-patients after treatment on a $\mathrm{O}$ normal carbohydrate diet. This variation in carbo- $工$ hydrate intake was not associated with the haem- $\vec{c}$ agglutination titre response. In addition, although $\subsetneq$ some of the patients had previously maintained low $\triangle$ weight by means of vomiting and purging, thus $\vec{\theta}$ fundamentally changing their metabolic status i 00 relation to the carbohydrate abstaining group of. anorecics (Crisp, 1970), this was not associated with any difference in the immune response.

The haemagglutinating inhibition titres are set out in Table 1 and illustrated in Fig. 1. The levels $\mathbb{Q}$ of antibody against all three influenza antigens on $\overrightarrow{\vec{P}}$ day 0 were similar, this is particularly significant $\frac{0}{3}$ because it means both groups had obviously a past history of infection and their baseline levels were

TABLE 1. The geometric mean titre, mean and standard deviation for the control group and those patients suffering from anorexia nervosa

\begin{tabular}{|c|c|c|c|c|c|c|c|}
\hline & \multicolumn{4}{|c|}{ Control Group } & \multicolumn{3}{|c|}{ Anorexia Nervosa Group } \\
\hline & Day & GMT & $\bar{X}$ & s.d. & GMT & $\bar{X}$ & s.d. \\
\hline A England $42 / 72$ & $\begin{array}{r}0 \\
10 \\
28 \\
50\end{array}$ & $\begin{array}{r}53 \\
211 \\
279 \\
279\end{array}$ & $\begin{array}{l}1 \cdot 723 \\
2 \cdot 325 \\
2 \cdot 455 \\
2 \cdot 445\end{array}$ & $\begin{array}{l}0.297 \\
0.518 \\
0.443 \\
0.260\end{array}$ & $\begin{array}{r}55 \\
139 \\
444 \\
463\end{array}$ & $\begin{array}{l}1 \cdot 743 \\
2 \cdot 144 \\
2 \cdot 636 \\
2 \cdot 666\end{array}$ & $\begin{array}{l}0.520 \\
0.582 \\
0.453 \\
0.494\end{array}$ \\
\hline A Hong Kong $1 / 68$ & $\begin{array}{r}0 \\
10 \\
28 \\
50\end{array}$ & $\begin{array}{r}84 \\
254 \\
320 \\
292\end{array}$ & $\begin{array}{l}1 \cdot 923 \\
2 \cdot 405 \\
2 \cdot 505 \\
2 \cdot 465\end{array}$ & $\begin{array}{l}0.267 \\
0.271 \\
0.254 \\
0.298\end{array}$ & $\begin{array}{r}76 \\
201 \\
670 \\
845\end{array}$ & $\begin{array}{l}1 \cdot 883 \\
2 \cdot 305 \\
2 \cdot 826 \\
2 \cdot 927\end{array}$ & $\begin{array}{l}0.618 \\
0.588 \\
0.502^{*} \\
0.578^{*}\end{array}$ \\
\hline A Port Chalmers $1 / 73$ & $\begin{array}{r}0 \\
10 \\
28 \\
50\end{array}$ & $\begin{array}{r}21 \\
127 \\
201 \\
211\end{array}$ & $\begin{array}{l}1 \cdot 321 \\
2 \cdot 104 \\
2 \cdot 304 \\
2 \cdot 325\end{array}$ & $\begin{array}{l}0.311 \\
0.405 \\
0.387 \\
0.391\end{array}$ & $\begin{array}{r}22 \\
55 \\
279 \\
335\end{array}$ & $\begin{array}{l}1 \cdot 341 \\
1 \cdot 743 \\
2 \cdot 445 \\
2 \cdot 525\end{array}$ & $\begin{array}{l}0.392 \\
0.439 * \\
0.604 \\
0.687\end{array}$ \\
\hline
\end{tabular}

GMT $=$ Geometric mean titre (antilog of $\bar{X})$.

$\bar{X}=$ mean of $\log$ titre values.

s.d. = standard deviation of mean of $\log$ titre value.

$* P<0.05$ using students $t$-test. 
the same. By day 10 the control subjects had higher titres of HA antibodies and the titres for antibodies against $\mathrm{A} /$ Port Chalmers/1/73 were significantly higher $(t=2.344 ; P<0.05)$ than the antibody levels in the test group. Thereafter, on day 28 and 50 the situation reversed with the test group of patients showing higher titres of antibody to A/England/42/72
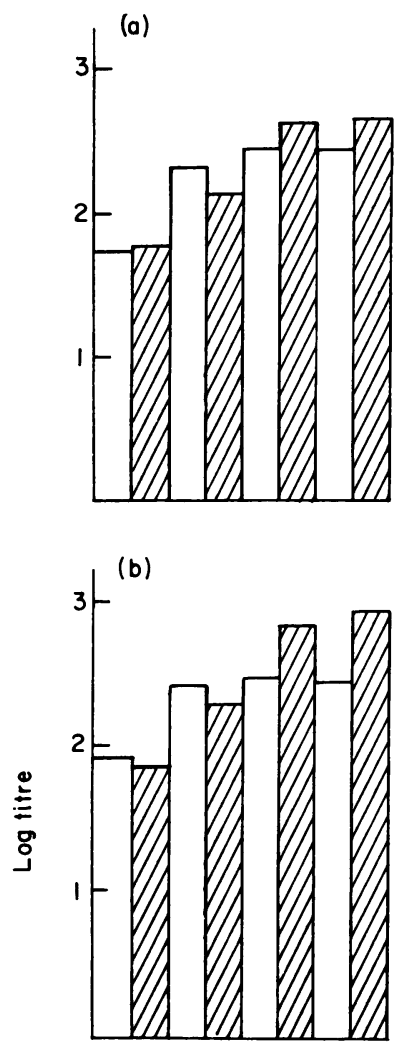

(c)

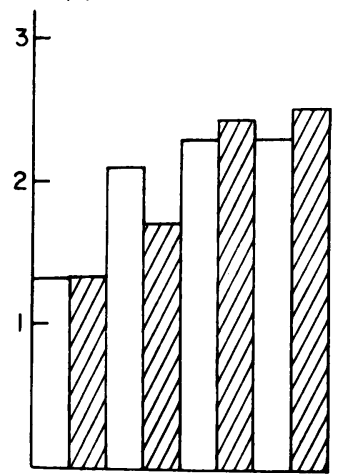

Fig. 1. Geometric mean titres of humoral antibody response to three influenza antigens. (a) England 42/72, (b) Hong Kong $1 / 68$ and (c) Port Chalmers 1/73. The shaded bars are the test group, the unshaded are the control group. and $\mathrm{A} /$ Port Chalmers/1/73 viruses, although the difference was not significant there was an increase in the expected direction. The increase in titre in response to $\mathrm{A} / \mathrm{HK} / 1 / 68$ at day 28 and 50 was, however, statistically significant $(t=2 \cdot 2098$;

$P<0.05)(t=2.7491 ; P<0.05)$.

\section{Discussion}

Anorexia nervosa is an illness which predominantly affects young women and is characterized by a tendency to manipulate diet to lose weight (Crisp, 1967). Amenorrhoea usually supervenes at an early stage. Two distinct groups are found clinically. The first, and more common, comprises those who lose weight by avoiding carbohydrate which, in extreme cases, may lead to a concomitant reduction in protein and fat intake. The second smaller group induce vomiting to lose weight or maintain a low weight. This group tend also to have periods of overeating, at which time their diet may contain large quantities of carbohydrate.

The nutritional disorder in anorexia nervosa is associated with manipulation of carbohydrate rather than lack of protein and is, therefore, not comparable to kwashiorkor. Both Russell (1968) and Crisp (1970) have shown that anorectics eat a diet containing adequate amounts of protein. Berkmann and Powell (1947) reported that serum albumin and globulin were mostly within normal range although one-third of the thirty-four patients, presumably vomiters, had levels lower than normal. Both Brothwood (1964) and Russell (1968) confirmed generally normal levels of plasma proteins although Russell showed a slight reduction in the rate of degradation of albumin and that protein depletion is more a feature of male anorexia nervosa. He suggested that, in females, fat propensity may protect them for protein depletion although the finding could be explained by the greater tendency of male anorectics to vomit as a means of controlling their weight.

In children suffering from kwashiorkor, Cohen and Hansen (1962) measured albumin and $\gamma$-globulin. They found that whilst albumin was reduced by about $50 \%$, the level and turnover of $\gamma$-globulin was relatively unaffected by the state of nutrition. In cases of kwashiorkor complicated by infection, however, the globulin synthesis rate was three times higher than that observed in unaffected children. The production of large amounts of $\gamma$-globulins by protein-depleted subjects suggests that $\gamma$-globulinforming cells preferentially utilize available amino acids, as a result, the synthesis of other biologically important proteins may be seriously limited and this may be the reason why the clinical manifestations of kwashiorkor are often precipitated by infection. Brown and Katz (1965) have challenged these 
findings; but McFarlane et al. (1970) found normal serum $\operatorname{IgA}$, IgM and IgC levels in children with kwashiorkor. In Najjar, Stephan and Asfour's (1969) study of immunoglobulins in marasmic infants, it was found that infants of 3-6 months had significantly higher levels of immunoglobulins compared with healthy infants of the same age. In older infants of 7-30 months, levels of IgA and IgM were significantly higher than the corresponding levels in well nourished infants.

Many authors have commented on the low levels of reproductive hormones in anorectics of low body weight. Russell (1970), reviewing this work, reported that on re-feeding, gonadotrophins and oestrogens tended to increase to almost normal levels but little cyclical activity was noted. Crisp and his colleagues have reported that low serum levels of reproductive hormones in anorexia at low body weight revert to normal values on re-feeding, although this capacity depended, in part, on their pre-morbid weight (Crisp et al., 1973; Palmer et al., 1975).

The possible relationship between gonadotrophic and gonadal steroid hormone and immunity is biologically interesting and relatively unexplored. Indications of the effect of oestrogens on immunity in animal experiments have been reported by Nicol et al. (1964). He found that oestrogenic hormones stimulate reticulo-endothelial cells in the uterus (Nicol, 1935), and further investigation indicated that the reticulo-endothelial system (RES) as a whole responded to stimulation by natural and synthetic oestrogenic compounds (Nicol et al., 1964). Nicol and his colleagues also showed RES activity varied at different stages of the oestrus cycle and during pregnancy in both rats and mice. It seems feasible therefore that the observed differences between the test and control group may be directly related to serum oestrogen levels and this possible relationship is worth further investigation.

In unpublished studies, Armstrong-Esther, Kean and Meerabux (1973) found raised serum levels of $\operatorname{IgM}$ and transferrin and decreased levels of $\operatorname{IgA}$ and IgG in women taking oral contraceptives. There appeared to be no significant change in the titre of IgA or IgM during the menstrual cycle but there was an increase in IgG. It is possible, therefore, that the effects of hormones, especially oestrogens, on IgG concentrations may be different from those on IgA or IgM. This could occur by action on the catabolic rate of IgG, which unlike that of $\operatorname{IgA}$ and IgM is directly proportional to its concentration and may involve a saturable protection system (Brambell, Hemmings and Morris, 1964). Several hormones may act upon the half-life role of the immunoglobulins; steroids reduce the levels of IgG, IgM and IgA, and IgG survival time is shortened (Waldmann, Bluese and Stroler, 1974).
Thyroxine also reduced the IgG survival time in

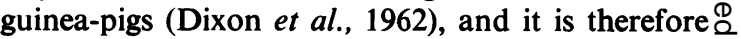
possible that the ovarian hormones may play a $\subseteq$. similar role.

Other possible mechanisms for the effect of $\frac{\vec{F}}{\square}$ oestrogen on immune responses may be related to $\frac{}{D}$ RNA-antigen complexes (Franzl, 1962), since RNA $\frac{\bar{\sigma}}{\bar{\omega}}$ synthesis is oestrogen-sensitive (Gorski and Nicolette, $\frac{\vec{\phi}}{\vec{\sigma}}$ 1963). Pre-menstrual decline in oestrogens also $\varrho$ leads to a decline in blood levels of vitamin $A$ क (Laurence and Sobel, 1953). Since vitamin A has $\vec{O}$ adjuvant properties (Jurin and Tannock, 1972) and increases the titres of certain antibodies, this $\vec{\sigma}$ may be an important factor in patients suffering $\frac{O}{0}$ from anorexia nervosa. The glucocorticoids also $\frac{0}{3}$ have a well known immuno-suppressive effect (Nicol and Snell 1956; Elliott and Sinclair, 1968); + it is possible that oestrogen may favour immuno- क् logical synthesis by decreasing the production of $N$ glucocorticoids. Oestrogen also prolongs the bio- $\mathcal{G}$ logical half-life of the adrenal corticosteroids (Yates $O$ and Urquhart, 1962; Tait and Burstein, 1964), their increased levels during pregnancy may be part of a $\bar{C}$ biological mechanism which according to Anderson (1971) prevents the development of maternal ${ }^{\infty}$ immunity against the fetus. By comparison, the $\vec{\varphi}$ stimulatory effect of oestrogens upon the RES he been well demonstrated by Nicol et al. (1964) in series of animal experiments. These workers hat also proposed that the human RES may be activated during the follicular phase of the menstrual cycle when repair and proliferation take place, and during $\stackrel{\varnothing}{\propto}$ the luteal phase as a protection against infection as $\overrightarrow{\vec{P}}$ the endometrium degenerates. Such fluctuations of $\frac{9}{3}$ activity in the RES during the menstrual cycle were first observed by Eufinger (1932). The latter would be of obvious importance as a defence $-\overrightarrow{0}$ mechanism and the former may increase the effective- 3 . ness of the immunological surveillance mechanism $\frac{0}{0}$ (Burnet, 1970) and thus decrease the risk of malignancy which is concomitant with any proliferative process.

The results of the study show an interesting 을 difference between the two groups and this may be $D$ related to the prepubertal status of the patients rather than their protein/caloric intake.

\section{Acknowledgments}

Admune influenza vaccine was kindly supplied by Duncan $N$ Flockhart and Co. Ltd, London. Viruses for anti-haemagglutination antibody estimation were kindly supplied by Dr G. C. Schild, National Institute for Medical Research, 0 Mill Hill, London. Fertile specific pathogen-free hen eggs $\frac{}{\mathbb{D}}$ for culture were obtained from Orchard Farm, Great $\stackrel{\mathcal{S}}{\rightarrow}$ Missenden, Buckinghamshire.

\section{References}

ANDERSON, J.M. (1971) Transplantation - Nature's success. Lancet, ii, 1077.

$$
\frac{0}{0.000}
$$


Berkmann, J.M. \& Powell, L. (1947) Clinical observations on starvation edema, serum protein and the effect of forced feeding in anorexia nervosa. Gastroenterology, 9, 357.

Brambell, E.W.R., Hemmings, W.A. \& Morris, I.G. (1964) A theoretical model of globulin catabolism. Nature. London, 203, 1352.

BRothwoOD, J. (1964) The plasma protein in anorexia nervosa. M.Phil. thesis. Institute of Psychiatry, University of London.

Brown, R.E. \& KATZ, M. (1965) Antigenic stimulation in undernourished children. East African Medical Journal, 42, 221.

BurNet, F.M. (1970) Immunity. In: Immunological Surveillance. Pergamon Press, London.

CoHen, S. \& HANSEN, J.D. (1962) Metabolism of albumin and globulin in kwashiorkor. Clinical Science, 23, 351.

Crisp, A.H. (1967) Anorexia nervosa. Hospital Medicine, (May) 713.

CrisP, A.H. (1970) Anorexia nervosa-feeding disorder, nervous malnutrition or weight phobia. World Review of Nutrition and Diet, 12, 452.

Crisp, A.H., Mackinnon, P.C.B., Chen, C. \& Corker, C.S. (1973) Observations of gonadotrophic and ovarian hormone activity during recovery from anorexia nervosa. Postgraduate Medical Journal, 29, 584.

CrisP, A.H., Palmer, R.L. \& Kalucy, R.S., (1976) How common is anorexia nervosa? A prevalence study. British Journal of Psychiatry, 128, 549.

Dally, P.J. (1969) Anorexia Nervosa. Heinemann, London.

Dixon, F.J., Talmange, D.W., Maurer, P.H. \& DeichMILLER, M. (1962) The half-life of homologous gamma globulin (antibody) in several species. The Journal of Experimental Medicine, 96, 313.

Elliotr, E.V. \& Sinclair, N.R. ST. C. (1968) Effect of cortisone acetate on $19 \mathrm{~S}$ and $7 \mathrm{~S}$ haemolysin antibody. Immunology, 15, 643.

Eufinger, H. (1932) Cited by Song, C.S., Rifkind, M.D., Gillette, P.N. \& Kappas, A. (1969) Hormones and the liver. American Journal of Obstetrics and Gynecology, 105, 813.

FranzL, R.E. (1962) Immunogenic sub-cellular particles obtained from spleens of antigen injected mice. Nature. London, 195, 457.

GoRski, J. \& Nicolette, J.A. (1963) Early estrogen effects on newly synthesized RNA and phospholipid in subcellular fractions of rat uteri. Archives of Biochemistry and Biophysics, 103, 418.
Hierholzer, J.C., Suggs, M.T. \& Hall, E.C. (1969) Standardized viral haemagglutination and haemagglutination inhibition tests. Applied Microbiology, 18, 824.

JURIN, M. \& TANNOCK, I.F. (1972) Influence of vitamin A on immunological response. Immunology, 23, 283.

Laurence, P.A. \& Sobel, A.E. (1953) Changes in serum vitamin A level during the human menstrual cycle. Journal of Clinical Endocrinology and Metabolism, 13, 1192.

McFarlane, H., Reddy, S., Adcock, K.J., Adeshina, H., COOKE, A.R. \& AKene, J. (1970) Immunity, transferrin and survival in kwashiorkor. British Medical Journal, 4, 268.

NajJar, S.S., Stephan, M. \& Asfour, R.Y. (1969) Serum levels of immunoglobulins in marasmic infants. Archives of Disabled Children, 44, 120.

Nicol, T. (1935) The female reproductive system in the guinea-pig: intravitam staining: fat production: influence, of hormones. Transactions of the Royal Society of Edinburgh, 58, 449.

Nicol, T. \& SNELl, R.S. (1956) Effect of cortisone on the reticulo-endothelial system. Nature. London, 177, 430.

Nicol, T., Bilbey, D.L.J., Charles, L.M., Cordingley, J.L. \& VeINON-ROBERTS, B. (1964) Oestrogen: the natural stimulant of body defence. Journal of Endocrinology, 30, 277.

Palmer, R.L., Crisp, A.H., Mackinnon, P.C.B., Franklin, M., Bonnar, J. \& Wheeler, M. (1975) Pituitary sensitivity to $50 \mu \mathrm{g} \mathrm{LH} / \mathrm{FSH}-\mathrm{RH}$ in subjects with anorexia nervosa in acute and recovery stages. British Medical Journal, $1,178$.

Rocklin, R.E., Meyer, O.L. \& David, J.R. (1970) An in vitro assay for cellular hypersensitivity in men. Journal of Immunology, 104, 95.

RusSell, G.F.M. (1968) Physiopathology of Adipose Tissue (Ed. by Vague, J.). Excerpta Medica.

RusSell, G.F.M. (1970) Modern Trends in Psychological Medicine (Ed. by Price, J.M.), 2nd Edn. Butterworth, London.

TAIT, J.F. \& Burstein, S. (1964) In vivo studies of steroid dynamics in man. In: The Hormones (Ed. by Pincus, G., Thinmann, K.V. \& Astwood, E.B.) Vol. 5, p. 441. Academic Press, New York.

WaldmanN, T.A., Bluese, R.M. \& Stroler, W. (1974) Plasma Protein Metabolism (Ed. by Rothschild, M.A. \& Waldmann, T.A.), p. 274. Academic Press, London.

YATES, F.E. \& URQuhart, J. (1962) Control of plasma concentrations of adrenocortical hormones. Journal of Physiology Review, 42, 359. 